\title{
Ciencia y evidencia.
}

\author{
Science and evidence.
}

Agustín Zerón*
$\mathrm{C}$ Oogito ergo sum es una frase reflexiva de René Descartes (1596-1650) que concreta un proceso intelectual y filosófico al afirmar que la única manera de encontrar la verdad es haciendo uso de la razón, «pienso, luego existo», tan solo pensar y dejar fluir ideas, ideas, ideas y más ideas hasta detonar una conclusión o al menos un razonamiento. Empirismo y escepticismo no son sinónimos, aunque ambos conceptos parten de una creencia determinada donde filosóficamente ambas buscan la verdad. Empirismo proviene de la palabra griega «empeiria», que se podría traducir como «experiencia»y también deriva en «experimento», por lo tanto, el empirismo es el conocimiento extraído sólo de la experiencia. El escepticismo es el pensamiento reflexivo «skeptomai», es la teoría del conocimiento que afirma la inexistencia de la verdad, o de existir, el ser humano no sería capaz de conocerla.

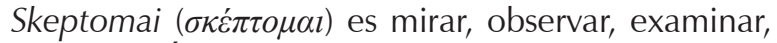
investigar, spek: de ahí las palabras como telescopio de

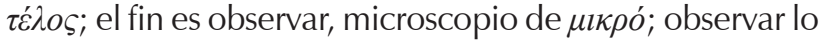
pequeño, o estetoscopio de $\sigma \tau \dot{\eta} \theta o \varsigma ;$ observar el pecho. El pensamiento es inductivo, deductivo, analítico, instintivo, interrogativo, racional, sistémico, convergente, divergente, simplemente es el pensamiento creativo (Figura 1).

Nadie podría negar el importante papel que ha tenido la ciencia en el desarrollo de vacunas contra el COVID-19. El desciframiento temprano del genoma del
SARS-CoV-2, su árbol filogénico, sus variables proteicas y, principalmente, el rápido desarrollo de la inmunización, particularmente las vacunas de RNA mensajero (mRNA) y las de vector viral que dan instrucciones a sus células inmunitarias, incluso los científicos han desarrollado las primeras «píldoras» contra COVID (molnupiravir, nucleósido sintético N-4 hidroxicitidina), todo es sólo un muestreo del valor de los avances científicos en los meses más recientes.

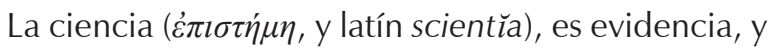
para encontrar evidencia se requiere investigación. La investigación es el proceso mediante el cual se adquiere el conocimiento, la investigación es el trabajo creativo y sistemático realizado para incrementar el acervo de conocimientos, obtener nueva información, con mayor profundización de los existentes o para resolver solución ante dudas provenientes del pensamiento y razonamiento analítico, encaminadas siempre a la elaboración de teorías o hipótesis, para que mediante actividades metodológicas tenga la capacidad de ser reproducibles. El método científico es el conjunto de tácticas para construir nuevos conocimientos con características de validación. Estas tácticas pueden ser mejoradas, y en su caso, reemplazadas por otras acordes a las actuales evidencias. Cada área de la ciencia, y cada investigación concreta, puede requerir un modelo propio y una determinada metodología. La epistemología, del

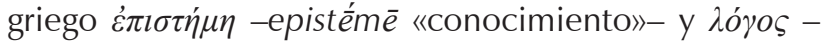
lógos «estudio»-, es la rama de la filosofía que estudia el conocimiento científico, su naturaleza, posibilidad, probabilidad, alcance y fundamentos.

* Especialista en Endoperiodontología. Editor en Jefe de la Revista ADM. México.

Citar como: Zerón A. Ciencia y evidencia. Rev ADM. 2021; 78 (5): 248-250. https://dx.doi.org/10.35366/102030

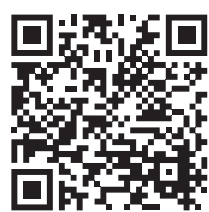


La evidencia (del latín, èvidens, «visible, evidente, manifiesto») es un conocimiento que con clara certeza y sin duda podemos calificarlo como verdadero. La investigación científica genera nuevas evidencias y por lo tanto aclara creencias para convertirlas en verdades y en aprendizaje científico. En medicina se usó por primera vez como concepto, de manera explícita. Con el surgimiento de la Medicina Basada en Evidencias se consideran aplicaciones o conocimientos verdaderos a los derivados de diversas investigaciones con un concepto aplicable a la Medicina Clínica, que actualmente se ha extendido a otros escenarios de la salud.

Desde 1966 la odontología entró contundentemente al campo de la investigación científica. Secularmente la práctica clínica era empírica basado sólo en la experiencia, pero los estudios longitudinales en el campo de la periodontología lograron sentar suficientes bases científicas para enmarcar la era de la odontología basada en evidencias (aún antes que otras áreas de la medicina). Actualmente es indudable que la medicina y la odontología deben continuar ampliando sus relaciones interdisciplinarias y profundizar los conocimientos multidisciplinarios para ejercer una práctica profesional más científica, más biológica, más sistémica y más transdisciplinaria. Todos los nuevos conocimientos a nivel global han cambiado para desarrollar paradigmas acordes al siglo XXI. Las más recientes aplicaciones clínicas y desarrollos tecnológicos provienen de las continuas investigaciones científicas dentro de un marco de ciencia traslacional. La European Society for Translational Medicine (EUSTM) en su declaración de intenciones han definido a la medicina traslacional como «una rama interdisciplinaria del área biomédica sustentada por tres pilares principales: el trabajo de laboratorio (benchside), el trabajo clínico (bedside) y el trabajo en la comunidad». Según la EUSTM el propósito de la medicina traslacional es combinar disciplinas, recursos, conocimientos y nuevas tecnologías para promover mejorías en la prevención, diagnóstico y tratamiento de las enfermedades globales. Esta definición considera a la medicina traslacional como un área fundamentalmente interdisciplinaria cuyo objetivo es aplicar los nuevos conocimientos científicos y las mejores aptitudes profesionales de diversa naturaleza con el propósito de mejorar sistemáticamente la atención de la salud global en beneficio de la humanidad. Debemos recordar que la salud oral es promover la salud global.

Los hitos más recientes de la investigación científica abarcan desde las tijeras genéticas de CRISPR, la inteligencia artificial para comprender a las diversas proteínas (DeepMind), los controladores de élite en los genomas y viromas, incluso el rápido desarrollo de las vacunas antiCOVID, han empleado ingeniería genética para obtener vectores virales y el mRNA de transferencia. Simplemente éstos son algunos ejemplos que no sólo han merecido el reconocimiento de pares, sino también la obtención del galardón internacional de un Premio Nobel, que se otorga cada año para reconocer a personas o instituciones que en el transcurso de sus actividades científicas hayan llevado a cabo investigaciones, descubrimientos o contribuciones notables para la humanidad, particularmente en física, química y medicina, pero también importantes

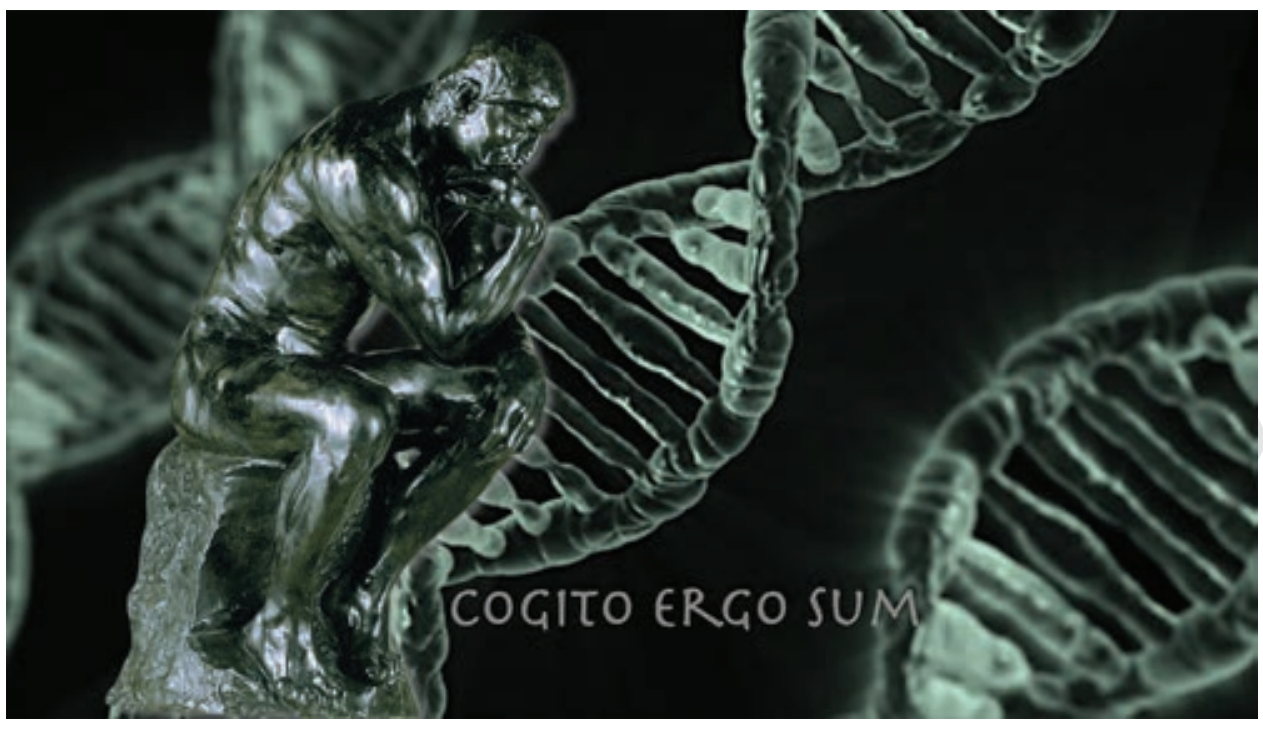

Figura 1:

Cogito ergo sum «pienso, luego existo», es una frase reflexiva que concreta un proceso intelectual y filosófico donde la única manera de encontrar la verdad es haciendo uso de la razón. 
en economía, literatura, y los que buscan que tengamos un mundo mejor y más pacífico.

México necesita continuar en ese mismo camino prioritario para fomentar la investigación científica y la formación continua de recursos humanos. Habrá quien postrado en la ignominia se atreva a decir que «investigar no tiene gran ciencia»... Ciencia es nuevo conocimiento. Es un conjunto de conocimientos obtenidos mediante la observación y el razonamiento sistemáticamente estructurados de los que se deducen principios y leyes generales con capacidad predictiva, y en principio, que sean comprobables experimentalmente. Ciencia es en esencia observacional, es un sistema que organiza y ordena el conocimiento a través de preguntas comprobables y respuestas demostrables.

Pienso, luego lo investigo, lo compruebo y lo publico, así es la ciencia.

La ciencia no es política, la ciencia no es democrática y mucho menos «neoliberal», aunque sistemáticamente la han politizado y estigmatizado hasta caer en una ideologización alienante sin bases sustentables. No hay duda y sí gran evidencia del ataque a la ciencia y rechazo sistemático a las academias, con un amplio sesgo de «anticientificismo republicano» y un endeble argumento para frenar el apoyo a científicos sólo por «la imposición de la lógica neoliberal en el ámbito ético» (sic). Los apoyos al sector científico han ido a la baja de forma significativa; en los años recientes los apoyos para la investigación y becas en el extranjero se han reducido en un 56\%. En el año 2019 el gobierno a través de CONACYT apoyó 1,734 proyectos de investigación y en 2020 sólo se financiaron 758 proyectos privilegiados. Y este año han querido retirar apoyos a más de 1,632 científicos de instituciones de educación superior. La investigación científica no compite con el despropósito de una investigación judicial por el uso «delincuencial» de fondos federales por parte del Foro Consultivo del CONACYT. Sirva que el «gremio organizado» académico y científico de México permanezcamos unidos ante la inconcebible e inquisidora acusación sin sustento y con un evidente tinte político de «Pienso... y con ellos me desquito».

Correspondencia:

Dr. Agustín Zerón

E-mail: periodontología@hotmail.com 